\title{
Study on the Curriculum Construction of Students in Software Requirements Engineering
}

\author{
Jie $\mathrm{Li}^{1, \mathrm{a}}{ }^{*}$ and Yunfeng Zhang ${ }^{1, \mathrm{~b}}$ \\ ${ }^{1}$ School of Computer and Remote Sensing Information Technology, North China Institute of \\ Aerospace Engineering, Langfang, Hebei 065000, China \\ a86389514@qq.com, ${ }^{\text {b4}} 42833769 @ q q . c o m$
}

\begin{abstract}
Keywords: Software requirement; Requirement engineering; Course construction; Improving measurements; Practice and evaluation
\end{abstract}

\begin{abstract}
Requirement engineering has been considered to be the most critical stages in the process of software engineering and it is critical to the success of software development. In the process of national and military information construction, how to obtain an accurate, describes the software requirements have been considered key and bottleneck to the construction of informatization. As engineering has high demand for personnel who are of great capabilities, such as technical skills, effective communication, problem solving ability, and social knowledge, thus it is facing various challenges in national and military information construction. Based on the new improvements of specifications such as Software Engineering Body of Knowledge (SWEBOK) and Software Engineering Education Knowledge (SEEK), we study how to improve the requirement of engineering courses to undergraduate and graduate students, propose a series of measures for improving the courses' knowledge organization, designing practice steps and course examinations, and finally discuss the implementation of these measures.
\end{abstract}

\section{Introduction}

With the development of software system, it is more and more complex, more and more large scale, people recognize the engineering way to put forward and describe the need. In the process of national and military information construction, how to obtain an accurate, describes the software requirements have been considered key and bottleneck to the construction of informatization. Whether military information systems and weapons equipment research and development personnel, or personnel needs, they all need to master relevant knowledge, the software requirement engineering is develop to meet the information unit and software needed for the modern war [1].

\section{The Present Situation and Problems of Software Requirement Engineering Course}

Wherever From the development of software engineering, requirement engineering has been considered to be the most critical stages in the process of software engineering, it is critical to the success of software development as any successful software needs to be accurately realize the user's needs, the needs of accurate and complete degree directly leads to the success of a software project. In addition, with the rapid expansion of the nowadays software scale growth and application of software, the software requirement is hard to get one-time and keep stable, demand continue to change in the software development process, resulting in the uncertainty of the software engineering process. In the software development process, it is generally held that the analyst personnel ability and quality of comprehensive requirements higher than code or software designers, because the demand of personnel in addition to the software running the essence and software development technology need to have in-depth understanding and rich experience, they also need to master the ability to communicate with customer skills, carding and integration of all kinds of information, and to understand the relevant national software may use the relevant laws, norms and customs etc. For 
example, the general process [2] of software industry development personnel occupation changes as shown in Fig. 1. We can see that the analyst personnel all have good experience in Software coding, software design and architecture design, in order to gradually adapt to the needs of work requirement engineering.

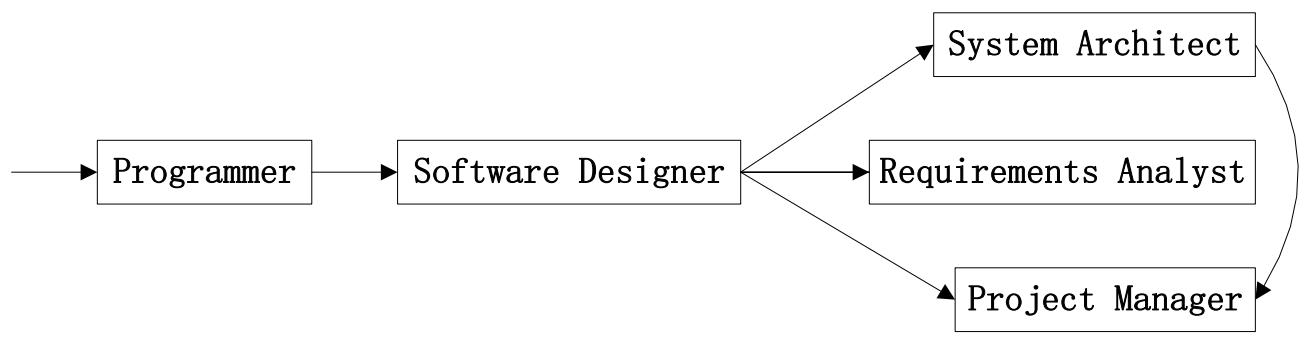

Figure 1. Finite element calculation model of arch dam and bedrock

Requirement engineering refers to the method and application of engineering technology and specifications to the development and management of software requirement. Compared with the traditional requirement analysis, requirement engineering outstanding engineering principle, emphasize systematic and ordinary, repeatable method and technology, improve the relevant activities and manageability of the process, and hope to reduce the demand for development and management of the difficulty and cost. At present, requirement engineering research and practice is still not mature enough, facing many problems to be solved and software requirement engineering courses teaching need the close combination of theory, method and engineering practice, so it has a higher degree of difficulty. From the current situation of the curriculum, courses in foreign universities and colleges pay more attention to the teaching of the theory, focus more on the requirement analysis and modeling based on the formal methods; China is more focused on engineering practice, the emphasis in traditional engineering use more demand acquisition and analysis. From the current research progress of the state, the army information construction urgent need of requirement engineering and requirement engineering. For software engineering undergraduate and postgraduate education, these two methods need further combined with the practical needs of integration and improved. Specifically, the software engineering course mainly includes the following problems and difficulties [3]:

(1) Requirement engineering is still a lack of universally accepted knowledge system, there are different methods and techniques in practical application, and there is not a unified standard in practical application, this has also led to the existing of the few requirement engineering textbook content difference is bigger, the choice of teaching content is very difficult.

(2) Compared with the design, implementation, testing, validation, proportion of software requirement engineering theory content is relatively small, more content, such as demand for, requirements, specifications, requirements, change management, etc., need to exchange, management skills and experience, it is difficult to teach in the classroom.

(3) The acquisition and analysis of demand is closely related with the field background, different application fields, such as transportation, financial, social, military, requires a deep understanding of the domain knowledge, it is a gap for only with the knowledge of computer science students.

(4) Software requirement analyst needs to have rich experience in software design, programming, and good capability of system view, the vision as well as the analysis summary, but due to shallow experience, students generally in these areas are lacking, so the curriculum teaching process exists the contradiction between the requirement of teaching and the students' basic.

(5) Students develop lots of the required abilities through a large number of engineering practices, because of the difference between these abilities, in the teaching process, considering the importance and the various elements of the scientific and rational design of the teaching experiment is very important.

(6) Due to good engineering practice is a combination of many kinds of ability, so we need indepth studies how to design scientific and reasonable evaluation system to comprehensive evaluation 
of student's ability to master the key technology of software requirement engineering methods and the ability level.

To solve these problems, we use the 3rd version of Software Engineering Body of Knowledge( SWEBOK) [4] released in 2014 by ACM and IEEE in software engineering courses for undergraduate and postgraduate students, and geared to the needs of the state, the army and currently the main needs of the development of information technology, we thought and practiced of curriculum content, practice, appraisal .etc in this paper, section 2 describes the design of teaching content for software requirement engineering, the third section discusses the practice and examination, the fourth section is the summary.

\section{The Construction of Software Engineering Course}

With more attention paid to the software engineering education, domestic and foreign made a lot of research work to the body of knowledge and education in recent years [5-8]. ACM and IEEE/CS developed Computing Curriculum-Software Engineering (CCSE) [9] in 2004, and Software Engineering Education Knowledge (SEEK) for undergraduate education is Included, ACM and IEEE/CS introduced the SWEBOK 3 edition [4] in 2014, it contains 15 fields of knowledge; China in 2006 formulated the "professional undergraduate computer science and Technology (software engineering)" [10]. In these specifications and tutorials, software requirement are part of them, including setting the related knowledge and curriculum requirement. The construction of our graduate program of software engineering in the undergraduate research and development continue to follow SWEBOK standards, and reflected the software requirement specification related knowledge to the curriculum content timely. The software requirement of domain knowledge and knowledge topic in the latest 3rd version of SWEBOK is shown in Table 1. Where, knowledge subarea 1-8 and knowledge topic is defined as the content of SWEBOK in the software requirement of knowledge domain, while $A$ and $B$ are two additional contents [11] according to the teaching needs. For each knowledge topic, we identify the knowledge topic in the setting of our current requirement engineering curriculum, mainly taught for undergraduate and postgraduate. The demand for engineering basic knowledge and the core concept, we teach in the undergraduate curriculum, and for some advanced knowledge we teach in the graduate courses. For some knowledge, the basic content in the undergraduate course teaching is the content of the more advanced teaching in graduate courses. 
Table 1 Sub-areas and topics of software requirement knowledge areas in SWEBOK

\begin{tabular}{|c|c|c|}
\hline Knowledge Sub-area & Knowledge Topic & Learning Phase \\
\hline \multirow{6}{*}{$\begin{array}{l}\text { 1. basis of Software } \\
\text { Requirement }\end{array}$} & $\begin{array}{l}\text { The definition of Software } \\
\text { Requirement }\end{array}$ & Undergraduate \\
\hline & Product and Process Requirement & Undergraduate \\
\hline & $\begin{array}{l}\text { Functional and Nonfunctional } \\
\text { Requirement }\end{array}$ & Undergraduate and Graduate \\
\hline & Emergent Properties & Graduate \\
\hline & Quantifiable Requirement & Undergraduate and Graduate \\
\hline & $\begin{array}{l}\text { System requirements and } \\
\text { software requirement }\end{array}$ & Undergraduate \\
\hline \multirow{4}{*}{ 2. Requirement process } & Process Model & Undergraduate \\
\hline & Process Participant & Undergraduate \\
\hline & Process Support and Management & Undergraduate \\
\hline & Process Quality and Improvement & Undergraduate and Graduate \\
\hline \multirow{2}{*}{ 3. Requirement Elicitation } & Source of Requirement & Undergraduate \\
\hline & Access to Technology & Undergraduate and Graduate \\
\hline \multirow{5}{*}{ 4. Requirement Analysis } & Requirement Type & Undergraduate \\
\hline & $\begin{array}{l}\text { Architecture Design and } \\
\text { Requirement Allocation }\end{array}$ & Graduate \\
\hline & Conceptual Modeling & Undergraduate and Graduate \\
\hline & Requirement Negotiation & Undergraduate \\
\hline & Formal Analysis & Graduate \\
\hline \multirow{3}{*}{$\begin{array}{l}\text { 5. Requirement } \\
\text { Specification }\end{array}$} & System Definition Document & Undergraduate and Graduate \\
\hline & $\begin{array}{l}\text { System Requirement } \\
\text { Specification }\end{array}$ & Undergraduate and Graduate \\
\hline & $\begin{array}{l}\text { Software Requirement } \\
\text { Specification }\end{array}$ & Undergraduate \\
\hline $\begin{array}{l}\text { 6. Requirement } \\
\text { Verification }\end{array}$ & Requirement Review & Undergraduate \\
\hline & Prototype & Undergraduate \\
\hline & Model Validation & Undergraduate and Graduate \\
\hline & Acceptance Testing & Undergraduate \\
\hline \multirow{5}{*}{ 7. Practical Considerations } & Requirement Process Iteration & Graduate \\
\hline & Management Change & Undergraduate \\
\hline & Requirement Attributes & Undergraduate \\
\hline & Requirement traceability & Undergraduate \\
\hline & Requirement Measurement & Undergraduate and Graduate \\
\hline $\begin{array}{l}\text { 8. Software Requirement } \\
\text { tools }\end{array}$ & Requirement Tool & Undergraduate and Graduate \\
\hline $\begin{array}{l}\text { A. Progress in } \\
\text { Requirement Engineering } \\
\text { Research }\end{array}$ & Frontier Achievements & Graduate \\
\hline \multirow{2}{*}{ B. Project Practice } & Domain Specific Requirement & Undergraduate and Graduate \\
\hline & Specific project practice & Undergraduate and Graduate \\
\hline
\end{tabular}

The needs of common engineering theory and technology, but also need to understand the latest progress in the field of requirement engineering, so in each class will special arrangements for a group of the latest requirement engineering research papers for students to read carefully, and 
assignment time for report by the students in the classroom, teachers and students discuss together with each other. Due to the requirement of engineering practice of high demand, and is closely related to specific areas, so the special arrangements for curriculum content, Military and special field or popular fields at home and abroad was described in the case of demand, to enable students to master the basic needs in the field, then they practice the project, complete tasks such as acquisition, analysis, specification, prototype, and report the result of the work in class. We show some knowledge topic and knowledge sub-area distinction of undergraduate and graduate courses through the following two examples:

(1) The requirement analysis course for the undergraduate is mainly about object-oriented requirement analysis, data flow oriented demand analysis, and the postgraduate courses will be target on Goal-oriented requirement analysis and solution-oriented requirement analysis, etc.

(2) For requirement modeling and specifications, the graduate course will relate to using object constraint language OCL and formal description language such as temporal logic, B method to extend the unified modeling language UML.

Through the comprehensive advantages of different software engineering specification, requirement engineering materials, combined with the recent developments in academia and industry requirement engineering, international well-known colleges and universities teaching content, in stressed the need for the acquisition, analysis, modeling, based on the specification and verification of main technical content, we further improve and integrate closely related to the requirement, such as engineering process management, psychology, sociology, communication, collaboration and other and necessary contents. We formed with independent knowledge system and teaching content, and has started writing software requirement engineering materials.

\section{Designation of the Software Requirement Engineering Practice and Evaluation}

Before the requirement engineering is the integration of software technology and communication skills, analytical ability, and document writing skills, it is to cultivate students' comprehensive quality. Cultivating numerous capacities in requirement engineering needs lot of engineering practice, due to the differences between these abilities, comprehensive consideration of the importance of the various elements, scientific and rational design of the teaching experiment is very important in the teaching process. In addition, due to the outstanding requirement analyst should have various abilities. Therefore we need in-depth study the course how to design a scientific evaluation system, to comprehensive evaluation for students to master the software requirement engineering methods and ability level. As demand analysis and is closely related to the field background, curriculum practice combined with specific application field is an important point we should consider. Therefore, we consider the following aspects in practice and evaluation of requirement engineering design:

(1) Combine the informationization development present situation and trend, select the era characteristics and typical representative significance of civil and military software, and construct a rich set of software requirement examples.

(2) Design rational grouping practice mechanism, including the needs of innovative software design, access and exchange between groups, group assessment and other aspects.

(3) Comprehensive consideration the needs of the mainstream engineering tools and excellent open source tools, establish advanced course practice teaching environment which closely to the industry development environment and support requirement analysis, modeling, verification and management effectively

(4) In accordance with the relevant international standards or the military specifications, military specifications for students practice process and final results, including the software requirement specification document format.

(5) Establish a scientific practical teaching evaluation method to evaluate students' practical process, results and mastered skills comprehensively.

In order to achieve the above goal and make the students comprehensive progress, Courses carries on the practice in the group project in the following way: 
Participants are encouraged to combine in the Internet, social networking, networking and other hot issues, military equipment and command and control information development trend, put forward the innovative practice cases and promote the innovative thinking.

Students make requirement proposal, requirement elicitation, requirement assessment between different groups, each group of students can play on the part of the user, development, review and other different role, promote the cultivation of students of different skills and ability of communication and collaboration.

Students make classroom presentation and discussion of analysis process, methods and results of the further rectification for the problems to strengthen the teaching of engineering practice.

Strengthen the connection between requirement acquisition, results of the analysis to the the software prototype implementation, the demand of engineering course results will eventually through demonstrable prototype system to display, so the demand of engineering course in the final results can be displayed by the prototype system.

Guided by the practice teaching reform content, using a modeling tool such as demand analysis RETools and other high academic level of open source software, Strengthen the laboratory construction of software and hardware platform related to requirement engineering.

For course examination, assessment of teachers refer to the basic theory, involved in requirement engineering situation as a user, the result of the implementation of requirement engineering(documents, reports, prototype, etc.) as a developer, the participation of presentations and discussions and expression ability and other various aspects of performance, the final comprehensive course grade is given.

\section{Conclusions}

After The effective implementation of requirement engineering as a current state and national defense information construction challenge, attracted widespread attention, comprehensive talents need a lot of grasp the needs of engineering process and technology requirement. China is badly in need of a large number of comprehensive talents which master the requirement engineering process and comprehensive requirement technology. As requirement engineering development soon and requirement as a bridge of communication between the computer world and real world, facing to all kinds of domain knowledge to meet the challenges of the complex software system needs continuous change, so the software requirement engineering courses construction face greater difficulties.

\section{Acknowledgments}

This paper is funded by research topic of North China Institute of Aerospace Engineering (No. JY2015-017), and funded by the professional comprehensive reform pilot project (No. ZG-2015-009).

\section{References}

[1] Dong Wei, Ning Hong, Qi Zhi-chang. Software engineering education for personnel of systematic warfare[J]. Journal of higher education research, 2010, 33(4): 30-32.

[2] Nakatani T, Tsunaki T, Tanait. Instructional design of a requirements engineering education course for professional engineers[J] .multimedia services in intel. Environ. SIST3: 119-151, 2010.

[3] Rafia Naz Memon, Siti Salwah Salim, Rodina Ahmad. Analysis and Classification of Problems Associated with Requirements Engineering Education: Towards an Integrated View[J]. Arabian Journal for Science and Engineering, 2014, 393.

[4] Abran A, Moore J W, Bourque P, et al.Guide to the software engineering body of knowledge(Version3.0)[Z] .Washington D.C: IEEE Computer Society, 2014.

[5] K. Olmos, J. Rodas. KMoS-RE: knowledge management on a strategy to requirements engineering[J]. Requirements Engineering,2014,194. 
[6] Azeddine Chikh. A Knowledge Management Framework in Software Requirements Engineering Based on the SECI Model[J]. Journal of Software Engineering and Applications, 2011, 0412.

[7] Liu Qiang, Chen Yue, Gu Tian-long, et al The teaching implementation of software engineering course $[\mathrm{J}]$ China University Teaching, 2011, 02: 41-44.

[8] Luo Bin, Wang Hao-ran, Ding Er-yu, Key course construction for software system-oriented software engineering course, China University Teaching, 2015, 02: 58-61.

[9] Association for computing machinery. Computing curriculum-software engineering[Z] .Washington D.C.: IEEE Computer Societ y, 2004.

[10] Steering Committee for computer science and technology of ministry of education, research report on computer science and technology development strategy in colleges and universities[M] .Beijing: Higher Education Press, 2006.

[11]Liao Li-ping, Liu Hong-ze, Ma Xiao-jun, et al The teaching reform of software engineering course for Applied Talents [J] Computer Education, 2014, 14: 19-21. 